\title{
Wither Participation and Empowerment?
}

\author{
Richard H. Price ${ }^{1}$ \\ University of Michigan
}

These articles represent a convergence of community research on participation with theoretical developments on empowerment. As a group, the papers extend conceptual models of empowerment and participation in a variety of ways by identifying individual and community perceptions, elements of the physical and social climate, and organizational characteristics as areas of study that broaden and connect the ideas of participation and empowerment. Theory and research on participation and empowerment still lack strong connections to other existing bodies of theory and do not yet focus adequately on the mechanisms by which individual groups and communities may become empowered. Empowerment and participation researchers have not yet explicitly acknowledged and explored the tensions that exist between partisan advocacy and scientific inquiry. These are challenges for the future.

This special section of the American Journal of Community Psychology marks a convergence of two interesting developments in the field of community psychology. First, we see the continuing trajectory of research and action projects developed by Wandersman and his colleagues including the earlier Neighborhood Participation project (Unger \& Wandersman, 1985; Wandersman, Jakubs, \& Giamartino, 1981) and, more recently, research based on the Block Booster Project described in this issue. Second, we see the growing interest in the field of community psychology in ideas of empowerment (Rappaport, 1984). The idea of empowerment has served as a rallying cry for a number of community psychologists and others interested in community and organizational change.

The convergence of these two developments is an important event. On the one hand, it provides research and action projects on citizen participa-

${ }^{1}$ All correspondence should be sent to Richard H. Price, University of Michigan, Ann Arbor, Michigan 48106-1248. 
tion with a new and emerging framework for the understanding of citizen participation. On the other hand, the citizen participation projects provide a grounding both in local action and empirical data for the idea of empowerment. How then does the convergence fare? Each of the contributions to this special issue represents a slightly different experiment in convergence.

In their article on the sense of community, Chavis and Wandersman (1990) make an ambitious attempt to articulate and bring together some elements of the concept of empowerment both in a theoretical model and in an empirical test of the model. The articulation itself is an important contribution. It matters less whether some elements of the model are confirmed in subsequent tests than that a model has been articulated at all. Other models and other tests are surely ahead, but Chavis and Wandersman have made a start and that is important.

Perkins, Florin, Rich, Wandersman, and Chavis (1990) offer us a second experiment in convergence between community participation and empowerment. One is immediately struck by the sophistication evident in the methodology of this piece of research. The use of multiple data sources and the analytic skill with which they are combined is admirable. Perkins et al. (1990) have worked carefully and deliberately toward the understanding of predictors of citizen participation and have identified both physical and social climate characteristics of blocks that account for a respectable proportion of variance in participation rates.

Perkins et al. acknowledge that there is a great deal more to be learned about the links between citizen participation and the control of crime, and crime is only one of many sequelae that one might pursue in understanding the consequences of community participation. Perkins et al. also make a crucial distinction between crime prevention efforts that may merely redistribute crime and participation-oriented approaches that have a more explicitly preventive impact. The distinction is crucial and should shape the framing of questions about crime prevention for both researchers and policy makers.

The article by Prestby, Wandersman, Florin, Rich, and Chavis (1990) is refreshing in its explicit appeal to theory. Prestby et al. draw on both social exchange and political economy perspectives and use these perspectives to organize research on the benefits and costs of participation. Their willingness to draw on existing theoretical frames to illuminate organizational actions and individual incentives for participation is commendable. Because of their rich interconnections with other literatures, theories of social exchange and political economy help illuminate and define the ideas of participation and empowerment. These theoretical frameworks also show their value in identifying relationships between antecedents and outcomes that appear robust, repeatable, and useful. 
Just as I had gotten deeply engaged in the subtleties of theory development and data analysis by reading these first three papers, I turned my attention to the action-oriented articles by Kaye (1990), the community organizer, and Burgess (1990), the Block Club president. One cannot read these articles without a breathtaking sense of how wide the gulf is between the culture of social science and the culture of community organizing and block leadership. As grateful as these two community leaders are for the help of the researchers, they also seem to feel frustration with their university-based colleagues when they seem more interested in defending the validity of their data than in community action. The tension between the two cultures of action and research is evident here. The articles by Kaye and Burgess also suggest that we might routinely ask community members for their theories of what is wrong with their community and how to make it right. Indeed, at the end of his comments Burgess offers his own theory of community participation and empowerment. My reading of his theory is that it is heavily interorganizational in its orientation and focuses on the relations between the block organization and citywide boards and police agencies. Burgess also acknowledges the importance and value of loyalty and vigilance within the community block club. This is a theory born out of successful experience by a Block Club president and therefore deserves attention. It is interesting to speculate on how we might combine the insights of community members with more formal theoretical formulations.

\section{CHALLENGES IN COMMUNITY PARTICIPATION AND EMPOWERMENT RESEARCH}

So what are we to say about this experiment in convergence, this alliance of community organizers, researchers of citizen participation, and empowerment theorists? On balance I judge the experiment to be a success, but like all experiments it raises important questions and identifies gaps in our thinking that should challenge us. I identify two problems that strike me as being in need of serious attention.

\section{Strengthening Participation and Empowerment Theory}

Community psychologists with an interest in ideas of participation and empowerment have a scholarly obligation. The obligation begins with the recognition that ideas of empowerment, power, and participation have a long tradition of research and theory in the social sciences. These traditions should inform our work, not merely as a matter of scholarly form but because they can instruct us about ideas already developed in other related 
fields. There is, for example, a large and diverse literature on power in social collectivities and organizations which ought to inform any discussion of empowerment (e.g., Kanter, 1972; Pfeffer, 1981). Similarly, there are now theories on the nature of social movements that could, but seldom do, inform our efforts to understand the nature and consequences of empowerment (e.g., Zald \& Useem, 1987). This is not merely a matter of academic footnotes. It is, instead, a matter of building on insights already achieved in order to extend the reach, clarity, and usefulness of our ideas.

There is a second theoretical problem to be worked out in the literature of empowerment. The verb, "to empower," is what Ryle (1949) called an achievement verb. That is, it is a word that denotes an outcome without in any way suggesting the antecedents, processes, or mechanisms by which the outcome is achieved (Sandelands, 1988). Achievement verbs of this kind are not helpful in pointing to the antecedents and processes that should be part of a theory of empowerment. These papers and still others in the future should be part of a process of theoretical elaboration of the concept of empowerment.

\section{Tensions Between Advocacy and Scientific Inquiry}

One of the core tensions in the field of community psychology is between the pursuit of scientific rigor, on the one hand, and the desire for improvement in the quality of community life. To say that there is a tension here is not to say that these goals necessarily contradict each other. But, in some cases the pursuit of one goal may compromise the other. For example, a powerful book by Baritz (1974) has argued that some social scientists have pursued a science shaped by corporate interests. Baritz contends that social scientists often framed their theories and problems in ways that shaped social inquiry to serve the ends of managers rather than workers. The irony is that much of this work was done without recognizing its explicitly normative nature. Certain ends were prescribed and others ignored. How can we guard against a similar myopia in the case of empowerment theory and research where the goals are quite different? What insights, tensions, and problems are lost to view when one espouses the goals of one group without an equal effort to appreciate the goals of other groups? Normative theory has a galvanizing effect, but does it also run the risk of revealing only part of the truth?

There is a related tension in participation research and empowerment theory. Do we want to empower everyone who is now without power in society? There are, for example, relatively powerless groups in some of our communities who advocate racial separatism and oppression. The fact of intergroup conflict is largely muted in the empowerment perspective though 
alluded to by Chavis and Wandersman (1990) in their article. Hard choices about who should be empowered and to what end are not yet part of the explicit agenda of empowerment theorists. Yet the existence of conflict, power, and politics in community and organizational life almost surely has to be acknowledged in future research and theory on empowerment.

This group of papers represents an important contribution to our understanding of community action and its consequences. Although formidable conceptual and practical challenges remain, the commitment to respond to these challenges is evident in these papers. I would welcome a similar set of contributions in half a decade as a way of charting how far we have come.

\section{REFERENCES}

Baritz, L. (1974). The servants of power: A history of the use of social science in American industry. Westport, CT: Greenwood Press.

Burgess, L. (1990). A block association president's perspective on citizen participation. Amercian Journal of Community Psychology, 18, 159-160.

Chavis, D. M., \& Wandersman, A. (1990). Sense of community in the urban environment: A catalyst for participation and community development. American Journal of Community Psychology, 18, 55-82.

Kanter, R. M. (1972). Commitment and community. Cambridge, MA: Harvard University Press.

Kaye, G. (1990). A community organizer's perspective. American Journal of Community Psychology, 18,

Perkins, D. D., Florin, P., Rich, R. C., Wandersman, A., \& Chavis, D. M. (1990). Participation and the social and physical environment of residential blocks: Crime and community context. American Journal of Community Psychology, 18, 151-158.

Pfeffer, J. (1981). Power in organizations. Marshfield, MA: Pittman.

Prestby, J. E., Wandersman, A., Florin, P., Rich, R. C., \& Chavis, D. (1990). Benefits, costs, incentive management and participation in voluntary organizations: A means to understanding and promoting empowerment. American Journal of Community Psychology, 18, 117-150.

Rappaport, J. (1984). Studies in empowerment: Introduction to the issue. Prevention in Human Services, 3, 1-7.

Ryle, G. (1949). The concept of mind. Chicago: University of Chicago Press.

Sandelands, L. E. (1988). The concept of work feeling. Journal for the Theory of Social Behavior, 18, 437-457.

Unger, D. G., \& Wandersman, A. (1985). The importance of neighbors: The social, cognitive, and affective components of neighboring. American Journal of Community Psychology, 13, 139-170.

Wandersman, A., \& Jakubs, J. F., \& Giamartino, G. A. (1981). Participation in block organizations. Journal of Community Action, 1, 40-48.

Zald, M. N., \& Useem, B. (1987). Movement and countermovement interaction: Mobilization, tactics and state involvement. In M. N. Zald \& J. D. McCarthy (Eds.), Social movements in organizational society (pp. 247-272). New Brunswick, NJ: Transaction Books. 